University of Wollongong

Research Online

Faculty of Engineering and Information

Faculty of Engineering and Information

Sciences - Papers: Part A

Sciences

$1-1-2015$

The optimisation of the secondary cooling water distribution with improved genetic algorithm in continuous casting of steels

\author{
Yu-Chun Zhai \\ Northeastern University \\ Ying Li \\ Northeastern University \\ Beiyue Ma \\ Northeastern University \\ C Yan \\ Northeastern University \\ Zhengyi Jiang \\ University of Wollongong, jiang@uow.edu.au
}

Follow this and additional works at: https://ro.uow.edu.au/eispapers

Part of the Engineering Commons, and the Science and Technology Studies Commons 


\title{
The optimisation of the secondary cooling water distribution with improved genetic algorithm in continuous casting of steels
}

\begin{abstract}
An improved genetic algorithm is presented for the water consumption of the secondary cooling zone based on the heat transfer model of the off-line bloom caster. This study is to control the existing cooling systems and the steel casting practises in order to produce steel with best possible quality. The fitness function of improved genetic algorithm is founded according to the metallurgical criteria. This algorithm coupled with heat transfer model and metallurgical criteria, added dynamic coding method and selfadapting mutation on the original genetic algorithm can increase water distribution adaptively and improve the process efficiency. The simulation results of T91 bloom show that the optimised distribution reduced by $2 \%$ of water consumption comparing to that of before optimisation. The maximum surface cooling rate and the rate of temperature rise reduced, and the equiaxed rate increases. The function is built for explaining the relationship between the casting speed and water distribution.
\end{abstract}

\section{Keywords}

algorithm, genetic, improved, steels, distribution, casting, water, cooling, secondary, optimisation, continuous

\section{Disciplines \\ Engineering | Science and Technology Studies}

\section{Publication Details}

Zhai, Y. Y., Li, Y., Ma, B. Y., Yan, C. \& Jiang, Z. Y. (2015). The optimisation of the secondary cooling water distribution with improved genetic algorithm in continuous casting of steels. Materials Research Innovations, 19 S26-S31. 


\section{Statement of novelty}

In this paper, an improved genetic algorithm is designed for the water consumption of the secondary cooling zone based on the heat transfer model of the off-line bloom caster. This algorithm coupled with heat transfer model and metallurgical criteria, added dynamic coding method and self-adapting mutation on the original genetic algorithm, can increase the simulated water distribution adaptively, improve the efficiency of the simulation process and the convergence ratio, and reduce the reheating between the zones. In the experimental, it is found that the water consumption after optimization reduced by $2 \%$, compared to that of before optimization. The maximum surface cooling rate and the rate of temperature rise reduced, and the equiaxed rate increases. Then a function is built for explaining the relationship between casting speed and water distribution, which can be the direction to control the cooling system in manufacturing process. So far, to our knowledge, although a lot of intelligent algorithms are used to optimize the secondary cooling conditions, but there are few reports on the simulation of this process with the developed algorithms. In this study, the improved genetic algorithm to optimize the secondary cooling water distribution is concerned, and the results show that the developed algorithm can save more water consumption with lower reheating and cooling rates. 


\title{
The optimization of the secondary cooling water distribution with improved
}

\section{genetic algorithm in continuous casting of steels}

\author{
Y.Y. Zhai ${ }^{1}$; Y. Li $^{* 1}$; B.Y. Ma; Z.Y. Jiang ${ }^{2}$ \\ 1: School of Materials and Metallurgy, Northeastern University, Shenyang 110819, China \\ 2: School of Materials and Mechatronic Engineering, University of Wollongong, Wollongong 2500, Australia \\ *Corresponding Author: liying@ mail.neu.edu.cn (Y. Li)
}

\begin{abstract}
An improved genetic algorithm is presented for the water consumption of the secondary cooling zone based on the heat transfer model of the off-line bloom caster. This study is to control the existing cooling system and the steel casting practice in order to produce steel with best possible quality. The fitness function of IGA (improved genetic algorithm) is founded according to the metallurgical criteria. This algorithm coupled with heat transfer model and metallurgical criteria, added dynamic coding method and self-adapting mutation on the original genetic algorithm, can increase water distribution adaptively and improve the process efficiency. The simulation results of T91 bloom show that the optimized distribution reduced by $2 \%$ of water consumption comparing to that of before optimization. The maximum surface cooling rate and the rate of temperature rise reduced, and the equiaxed rate increases. The function is built for explaining the relationship between the casting speed and water distribution.
\end{abstract}

Keywords: Continuous casting, Secondary cooling, Water distribution, Genetic algorithm, Self-adapting mutation

\section{Introduction}

Continuous casting technology, a main method in steelmaking industry, has been rapidly developed in recent years. In this process, liquid steel from tundish is poured into mold to form billets, blooms or slabs. Since the cooling conditions at the mold and air cooling zone are relatively stable for a given caster, with only the secondary cooling zone (SCZ) capable of being adjusted within a wide range, the quality and output of casting is closely related to the SCZ. Given that the cooling process removes the superheat and the latent heat of fusion at the solidification front, the main cause of internal crack, surface crack and center segregation is the unreasonable secondary cooling structure. These defects should be avoided for the sake of competitiveness in manufacturing. Thus, it is critical to control and optimize the secondary cooling in the whole casting process. It is not feasible to conduct a lot of experimental trials to calculate the influence of different operational parameters due to economic reasons. Mathematical models and optimization algorithms are useful tools for the optimization of water distribution in the SCZ. The heat transfer model is the foundation of the optimization of the SCZ. This model is an initial boundary problem of partial differential equation (PDE). It cannot be solved using analytical method and also the computational time solution is too long. In the secondary cooling process, the value function of metallurgical criterion is complicated, and the efficiency of general optimization method is low.

The traditional method for solving the optimization problem of the secondary cooling process is complex nonlinear optimization problem with poor efficiency. Intelligent optimization algorithm has been rapidly developed in secondary cooling water distribution, which is an important factor affecting the quality of the bloom. The improper distribution of water will make surface cracks, the 
crack in the middle, the center of the crack, the crack corner, bulging and so on. They will seriously affect the production and product quality finishing process. A number of intelligent optimization methods used in the secondary cooling process have been developed rapidly. Lally et al. used an optimization method with heat flow and solidification model to determine the parameters that maximize the quality of final product of billet and slab casters [1-2]. Santos et al. developed an intelligent optimization method of genetic algorithm (GA) with finite difference heat transfer model based on the metallurgical criterion and maximum withdraw speed to control the secondary cooling zone of slab continuous casting, and heuristic search algorithms were used to minimize the consumption water and the smooth temperature gradient in the secondary cooling process [3-5]. A model optimization of billet continuous casting steel secondary cooling with an implicit enthalpy mathematical solidification was developed to calculate three dimensional and stationary temperature fields and to decrease center segregation [6]. An approach based on Hamilton-Jacobi-Bellman equation satisfying the value function has been used to the optimal problem of the SCZ with water spray control of a low-carbon billet caster [7]. Chakraborti et al. solved the pertinent transport equations in the mold of continuous caster using a finite volume approach with genetic algorithms. The results showed significant improvements of the casting velocity and the solidified shell thickness [8]. Meng et al. proposed an enhanced particle swarm optimization algorithm to optimize the secondary cooling of billet, which has been reported with good convergence rate and convergence precision [9].

This study presents an optimization model for controlling the water intensities of the water in the $\mathrm{SCZ}$ of bloom caster. Considering the simulation condition, a heat transfer model of bloom caster is applied using an analytical solution for the temperature profile. Then an improved genetic algorithm, which contains byte type dynamic coding method and self-adapting mutation, is used to code the secondary cooling water distribution. The procedure corresponds to the fitness function determined by highly conflicting technological and metallurgical requirements. These methods increase the distribution adaptability and improved the efficiency, comparing with the traditional optimization methods of solving multi-objective optimization and other non-linear problems. In the present study, the secondary cooling water distributions are optimized in different casting speeds, and then the function of second cooling optimal water distribution and casting speed is obtained. This model improved the equiaxed rate of the bloom and reduced the maximum surface cooling rate and the rate of temperature rise. As a result, the optimized bloom has better quality.

\section{The Mathematical Optimization Model}

The state system used in the present study is a two-dimensional heat transfer model in which the heat conduction to the withdrawal direction is neglected. It is because that the withdrawal rate of steel is relatively high and the thermal conductivity is low. The heat transfer model is developed and applied to calculate the temperature distribution and solid shell thickness profile of bloom continuous casting. It is the foundation of the optimization of secondary cooling zone. The optimization module of the water distribution of secondary cooling zone using Genetic Algorithm is established according to the metallurgical criteria for bloom and target temperature controlling principle.

Suppose that the cross section of the bloom is a rectangular, $\Omega=[0, a] \times[0, b]$, which is moving along the $z$ direction with a constant speed. Let $T(x, y, t)$ be the temperature at the point $(x, y, t)$. Then $T$ satisfies the following nonlinear heat conduction equation with boundary conditions [10]. 


$$
\left\{\begin{array}{c}
\operatorname{div}(k(T) \nabla T)=\rho(T)[c(T)+L f(T)] \frac{\partial T}{\partial t},(x, y) \in \Omega, 0 \leq t \leq t_{\text {end }} \\
-k(T) \frac{\partial T}{\partial n}=q(x, y, t, W),(x, y) \in \Gamma \\
T(x, y, 0)=T_{\text {mold }}
\end{array}\right.
$$

where $\Gamma$ is the boundary of $\Omega, c(T)$ is the specific heat, $\rho(T)$ is the density, and $k(T)$ is the thermal conductivity. $T_{\text {mold }}$ is the pouring temperature at the beginning of the mold, $n$ is the outward normal unity vector of $\Gamma, L$ is the latent heat and $f$ is the function of the solid-phase fraction variation with temperature, $q$ is the heat flux on the boundary. All these parameters are assumed to be bounded, positive and differentiable.

The heat of liquid iron is transferred from the surface in the continuous casting process. The cooling water flow rate temperature is difference between the inlet and outlet of the mold. The average heat flux in the mold can be described by Eq. (2).

$$
\bar{q}=\frac{c Q \Delta T}{L_{\text {mold }}}
$$

where $c$ denotes the specific heat capacity of steel, $Q$ denotes the water flow rate of the mold, $\Delta T$ denotes the water temperature difference between the inlet and outlet of mold, $L_{\text {mold }}$ denotes the effective cooling region of mold.

In the secondary cooling zone after the mold the model has been divided into calculation domains between a pair of support rolls. The boundary conditions in the secondary cooling zone can be expressed by Eq. (3). The heat transfer coefficient is a function of the flux of the spraying water, which is given by Eq. (4). W is cooling water flux, and $T_{\mathrm{w}}$ denotes cooling water temperature.

$$
\begin{gathered}
q=h\left(T_{b}-T_{w}\right) \\
h=395.2 W^{0.55}\left(1-0.0075 T_{w}\right) \\
h=0.35 w+0.13
\end{gathered}
$$

The air cooling zone is deposed as boundary of radiation:

$$
q=\varepsilon \sigma\left(\left(T_{b}+273\right)^{4}-\left(T_{e}+273\right)^{4}\right)
$$

where $\varepsilon$ represents radiation coefficient, $\sigma$ is Stefan-Boltzmann constant, $T_{\mathrm{b}}$ is the strand surface temperature and $T_{\mathrm{e}}$ is environment temperature.

Because of the slab cross-section symmetry, a quarter of the cross-section is taken as the object. Combined with the heat transfer boundary conditions, the explicit finite difference method is applied to discrete Eq. (1) solved by the speedup method.

\section{Metallurgical criteria}

The surface quality is related to the fluctuations of the surface temperature, the reheating temperature between zones and the cooling ratio. Fluctuations of surface temperature, is easy to produce thermal stresses, causing surface quality problems. The reheating temperature between 
zones will lead to the increase of the solidification front to generate internal heat stress cracks, and if the surface temperature reduces too fast, it will facilitate the expansion of cracks, or make surface in the low ductility stage, to generate new crack under thermal stress and mechanical stress, and exacerbated bloom quality. The optimization model is based on the metallurgical criteria. In this paper, the criteria are established as follows. The fitness function of improved GA is based on the metallurgical criteria [11], which affects the optimization process and results.

1. Surface temperature

The actual temperature $T_{m, i}$ should be closed to the target temperature $T^{*}$ based on the manufacturing technique. The function value should be as smaller as possible.

$$
f_{1}(h)=\int_{0}^{L}\left(T_{m, i}(h, z)-T^{*}(z)\right)^{2} d z
$$

2. Metallurgical length

The solidification of the ingot has to be complete before the liquid core length $L_{\mathrm{M}}$, in order to avoid internal and transversal cracking and centerline segregation. Complete solidification is the best approach for this type of positional constraint applied to the unbending point $L_{\mathrm{d}}$.

$$
f_{2}(h)=\operatorname{Max}\left(0, L_{M}-L_{d}\right)^{2}
$$

3. Water flow

The physical constraints are simple upper and lower bounds on the variables, such as casting speed and water flow rates for mold and sprays zones. The water flow rate in a given sprays zone has a lower and an upper limit depending on the hydraulic system, which is given into heat transfer terms. The sequence of priority is modifying casting speed and spays water flow. The water flow of each sprays zone $h_{i} \leq h_{\text {max }, i}$.

$$
f_{3}(h)=\sum_{i=1}^{n} h_{i}
$$

4. Unbending temperature

In this manufacture system of the high chrome irons, the lower limit of low ductility trough for steels is usually located at $700-750^{\circ} \mathrm{C}$. The upper limit of the low ductility trough corresponds to the transition between transgranular and intergranular fractures. Depending on the steel composition, this upper temperature limit can vary from 900 to $1100^{\circ} \mathrm{C}$.

Limiting the surface temperature above the upper limit of the low ductility region, transversal cracking is also reduced. Longitudinal crack at the unbending point is the most common in steels with carbon contents between $0.18 \mathrm{wt} \%$ and $0.21 \mathrm{wt} \%$, the maximum value observed being 0.19 $\mathrm{wt} \%$. In this study, the strand surface temperature is considered to be kept the above upper limit of low ductility temperature.

$$
f_{4}(h)=\operatorname{Max}\left(0, T_{c}-T(t, h)\right)^{2}
$$

5. Reheating between zones and the cooling ratio

The reheating effect will happen when the bloom passes from a cooling zone with a high heat transfer coefficient to lower one, and must be limited as a function of steel grade and casting operating parameters. The reheating leads to the development of tensile stress at the solidification front, which can induce cracking. The maximum permissible reheating rate $C_{\mathrm{p}}$ and the maximum cooling ratio $C_{\mathrm{N}}$ along the machine are chosen to be $100^{\circ} \mathrm{C} / \mathrm{m}$ and $200^{\circ} \mathrm{C} / \mathrm{m}$ in order to avoid 
midway surface cracking.

$$
f_{5}(h)=\int_{0}^{L} \operatorname{Max}\left[\frac{\partial T(h, z)}{\partial z}-C_{P}, 0\right]^{2} d z+\int_{0}^{L} \operatorname{Max}\left[C_{N}-\frac{\partial T(h, z)}{\partial z}, 0\right]^{2} d z
$$

Since the differences between units of objective functions, it is to make the objective functions uniformization. The different weighted coefficients $\omega_{i}$ are chosen according to the impact on the quality of casting bloom. The uniformizable evaluation function is expressed by Eq. (12).

$$
f(h)=\operatorname{Min} \sum_{i=1}^{5} \omega_{i} f_{i}(h),\left(\sum_{i=1}^{5} \omega_{i}=1\right)
$$

The optimization control strategy is to search control vector quantity $h=\left[h_{1}, h_{2}, \cdots h_{n}\right]^{T}$ ( $n$ denotes the number of sprays cooling zones), to make the function value as smaller as better.

\section{The Improved Genetic Algorithm of SCZ}

Genetic algorithms are highly robust computing techniques, which have been widely used in a context far-fetched from biology of any kind [12]. The GAs widely use in iron and steel manufacturing process $[13,14]$. Most GA forms contain the variables that are mapped on to their binary equivalents. These variables are concatenated together to form an individual and a set of individuals to form a population. Each member of the population therefore carries a potential solution of the problem. The initial population is generated randomly. In the secondary cooling zone, improved genetic algorithm that incorporates with optimization strategies of determining the best operational parameters to the continuous caster is developed.

Fig. 1 shows the improved genetic algorithm (IGA) procedure builds on the traditional GA. The whole structure is basically composed of three operating blocks. The first block consists of the numerical heat transfer model that generates results of simulations as a function of the input parameters related to operational conditions. The second block is built on the continuous casting process containing a set of critical and limiting operational conditions imposed by metallurgical constraints. The decision block is systematically compared to the simulations, modifications of the input variables. Such modifications are performed by observing the functional limits of each variable. In contrast to the traditional algorithm, it is not necessary for GA to solve the differential coefficient of objective function. This algorithm with adopted probabilistic method is used to solve the problem that is difficult to obtain the derivative value of the objective function.

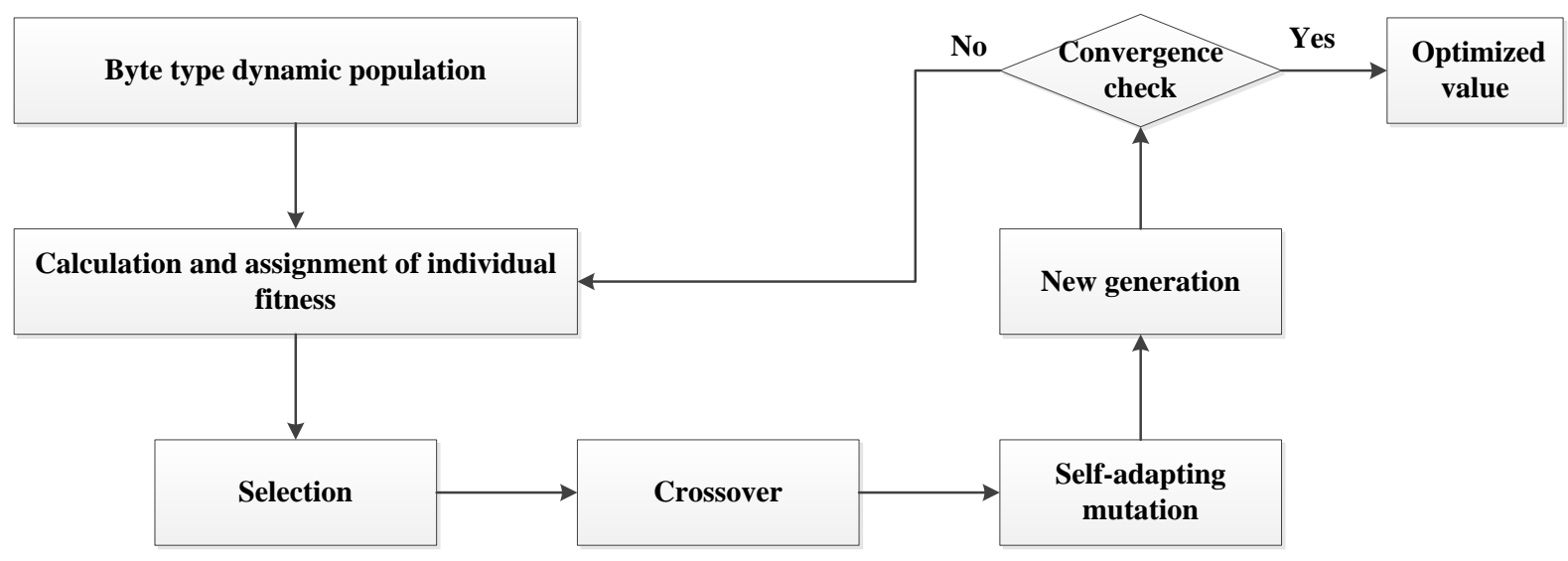

Fig. 1 Schematic diagram of the IGA procedure 
In the IGA process, byte type dynamic coding method and self-adapting mutation are used to improve the global and local searching ability, and the searching efficiency of GA with the basis of keeping the best value in the group renewal process.

The IGA includes several steps, including generating an initial byte type dynamic coding population by using the input parameters, computing cost function, storing parameters setting; modifying cooling conditions in each region where the constraint was violated, applying a genetic operator to determine new parameter of process, and generating new results.

All the constraint conditions of the individual in the process of generating initial population are verified by the apriori method. This method can accelerate the optimized process and global convergence, and plays a reference role in picking up the penalty factor and the weighting function. Byte type dynamic coding method is an efficient coding method that couples with binary method and dynamic method. It is considered as having high search capability, optimal robustness and local convergence. Self-adapting mutation can make crossover and dissociation self-adapting change along with the fitness of individual size. This algorithm is likely to result in large mutation probability in the initial stage, which is used to produce new individual. In the late stage, it is used to local search because of low mutation probability.

In the self-adapting mutation, the self-adapting value is adjusted by the equations as follows.

$$
\begin{aligned}
& p_{c}=\left\{\begin{array}{c}
k_{1} \frac{f_{\max }-f^{\prime}}{f_{\max }-f_{\text {avg }}}, f^{\prime} \geq f_{\text {avg }} \\
k_{2}, f^{\prime}<f_{\text {avg }}
\end{array}\right. \\
& p_{m}=\left\{\begin{array}{c}
k_{3} \frac{f_{\text {max }}-f}{f_{\text {max }}-f_{\text {avg }}}, f \geq f_{\text {avg }} \\
k_{4}, f<f_{\text {avg }}
\end{array}\right.
\end{aligned}
$$

where $p_{\mathrm{c}}$ is the crossover rate, $p_{\mathrm{m}}$ is the mutation rate, $k$ is a constant, $f_{\max }$ is the maximum fitness value, $f_{\text {avg }}$ is the average fitness value, $f$ is the larger one of the crossover, and $f$ is the mutation fitness value.

\section{Application and Discussion}

The improved GA coupled with the heat transfer model has been applied in a bloom caster. The steel grade is T91, and the bloom size is $425 \times 320 \mathrm{~mm}^{2}$. The casting speed is $0.65 \mathrm{~m} \mathrm{~min}^{-1}$. The casting temperature is $1556^{\circ} \mathrm{C}$, and the liquid and solid temperatures are 1498 and $1368^{\circ} \mathrm{C}$, respectively. The cold water temperature is $25^{\circ} \mathrm{C}$. The specific heat of T91 steel is $560 \mathrm{~J} \mathrm{~kg}^{-1} \mathrm{~K}^{-1}$, the thermal conductivity of solid phase is $26 \mathrm{~W} \mathrm{~m}^{-1} \mathrm{~K}^{-1}$, and the density is $7708 \mathrm{~kg} \mathrm{~m}^{-3}$.

The heat transfer model calculates temperature distribution and shell thickness using offline procedure parameters. Fig. 2 describes the whole process with heat transfer model coupled with IGA. Because the temperature in the SCZ cannot be measured, the method to validate the model is shooting nail, measuring the temperature in the air cooling zone.

The parameters of the IGA optimized process are designed the initial population is 30 , the maximize number of evolutionary computation is 100 , the length of chromosome is 128 , and the individual number is 4 . The initial crossing-over rate, mutation rate are $0.75,0.05$ respectively, and they will be recomputed by Eqs.(13) and (14) during the IGA process. Compared to the original GA, the improved GA can be convergent more quickly and have the best searching ability for optimized 
solution. In Eq. (12), the weight coefficients of Eqs. (7-11) are 0.4, 0.1, 0.3, 0.1 and 0.1, respectively.

Fig. 3(a) shows a comparison between the surface and central temperatures before and after optimization. The optimization target based on the metallurgical criteria is shown in Fig. 3(a), the maximum surface cooling rate is $38^{\circ} \mathrm{C} / \mathrm{m}$ before optimization, down to $32^{\circ} \mathrm{C} / \mathrm{m}$. The maximum surface reheating rate is $97^{\circ} \mathrm{C} / \mathrm{m}$ before optimization, down to $89^{\circ} \mathrm{C} / \mathrm{m}$ after optimization. The optimized water distribution is more reasonable, which reduces stress cracks. It is consistent with the metallurgical criteria. The cooling rate after optimization decreased by $2{ }^{\circ} \mathrm{C} / \mathrm{m}$, and the rebound rate decreased by $3^{\circ} \mathrm{C} / \mathrm{m}$. The lower reheating and cooling rates are beneficial for the quality of the bloom.

Fig. 3(b) shows the shell thickness before and after optimization. The liquid length reduced by $0.3 \mathrm{~m}$ after optimization.

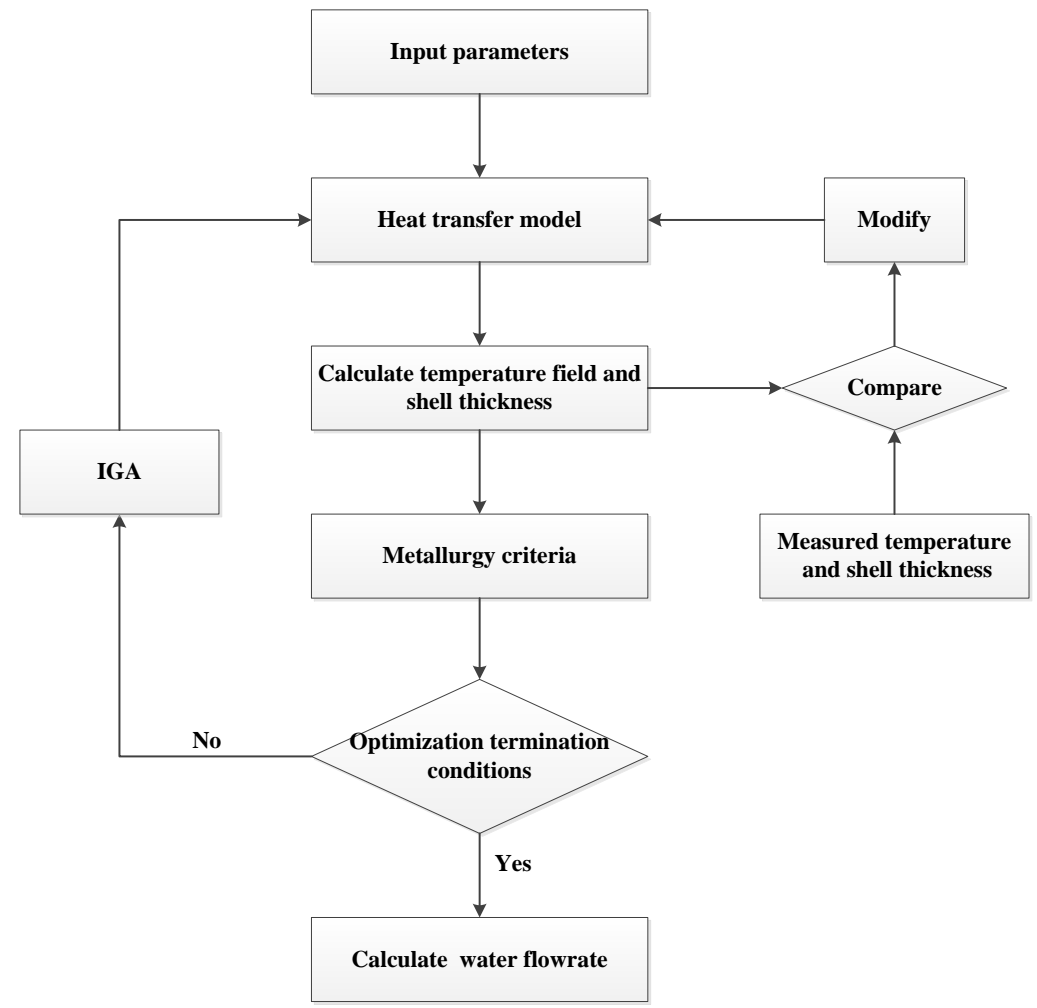

Fig. 2 Schematic diagram of the heat transfer model
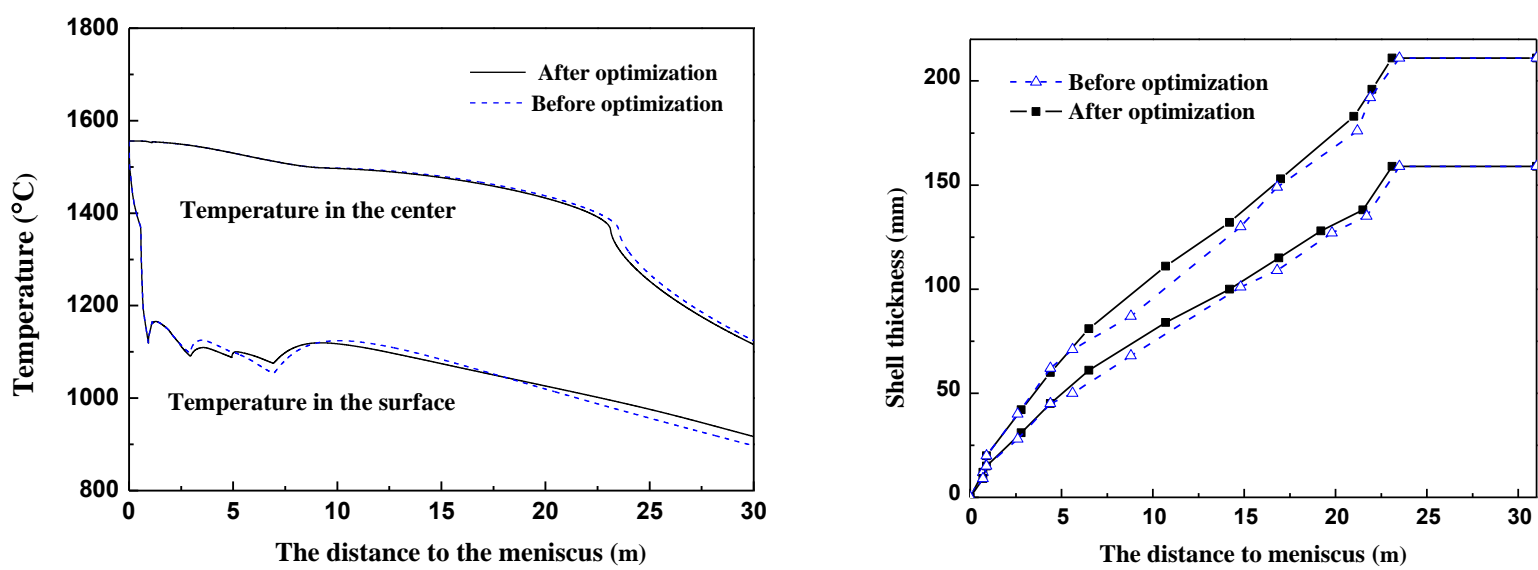

(a) Strand temperature
(b) Shell thickness

Fig. 3 Strand temperature and shell thickness before and after optimization with casting speed of $0.6 \mathrm{~m} \mathrm{~min}^{-1}$

The secondary cooling water data after optimization compared to the data before optimization are shown in Table 1. The decreasing trend of the optimized water distribution by piecewise, and the water distribution eventually develops to be a reasonable status. The stress elements that induce cracks are considerably reduced. The water after optimization is decreased by $2 \%$, compared to that of before optimization. The difference becomes smaller between the average temperatures of each section and the target temperature in accordance with the metallurgical criterion. The result is coincident with the need of improving the bloom quality in the secondary cooling process.

It can be determined that the relationship function between the optimized water and casting speed based on the heat transfer model and IGA. The conic of each secondary cooling water distribution using least squares method is shown in Fig. 4. It will be a guidance of static water distribution in the actual continuous casting.

Table 1. The optimized secondary cooling water section with Genetic Algorithm

\begin{tabular}{ccccccc}
\hline $\begin{array}{c}\text { Average water } \\
\left(\mathrm{L} \mathrm{min}^{-1}\right)\end{array}$ & CZ1 & CZ2 & CZ3 & CZ4 & $\begin{array}{c}\text { Casting speed } \\
\left(\mathrm{m} \mathrm{min}^{-1}\right)\end{array}$ & $\begin{array}{c}\text { Total water } \\
\left(\mathrm{L} \mathrm{min}^{-1}\right)\end{array}$ \\
\hline Before optimization & 45 & 44 & 21 & 10 & 0.55 & 120 \\
After optimization & 42 & 46 & 18 & 11 & & 117 \\
Before optimization & 53 & 51 & 24 & 12 & 0.60 & 140 \\
After optimization & 48 & 55 & 20 & 13 & & 136 \\
Before optimization & 57 & 54 & 26 & 13 & 0.65 & 150 \\
After optimization & 53 & 56 & 21 & 14 & & 144 \\
\hline
\end{tabular}



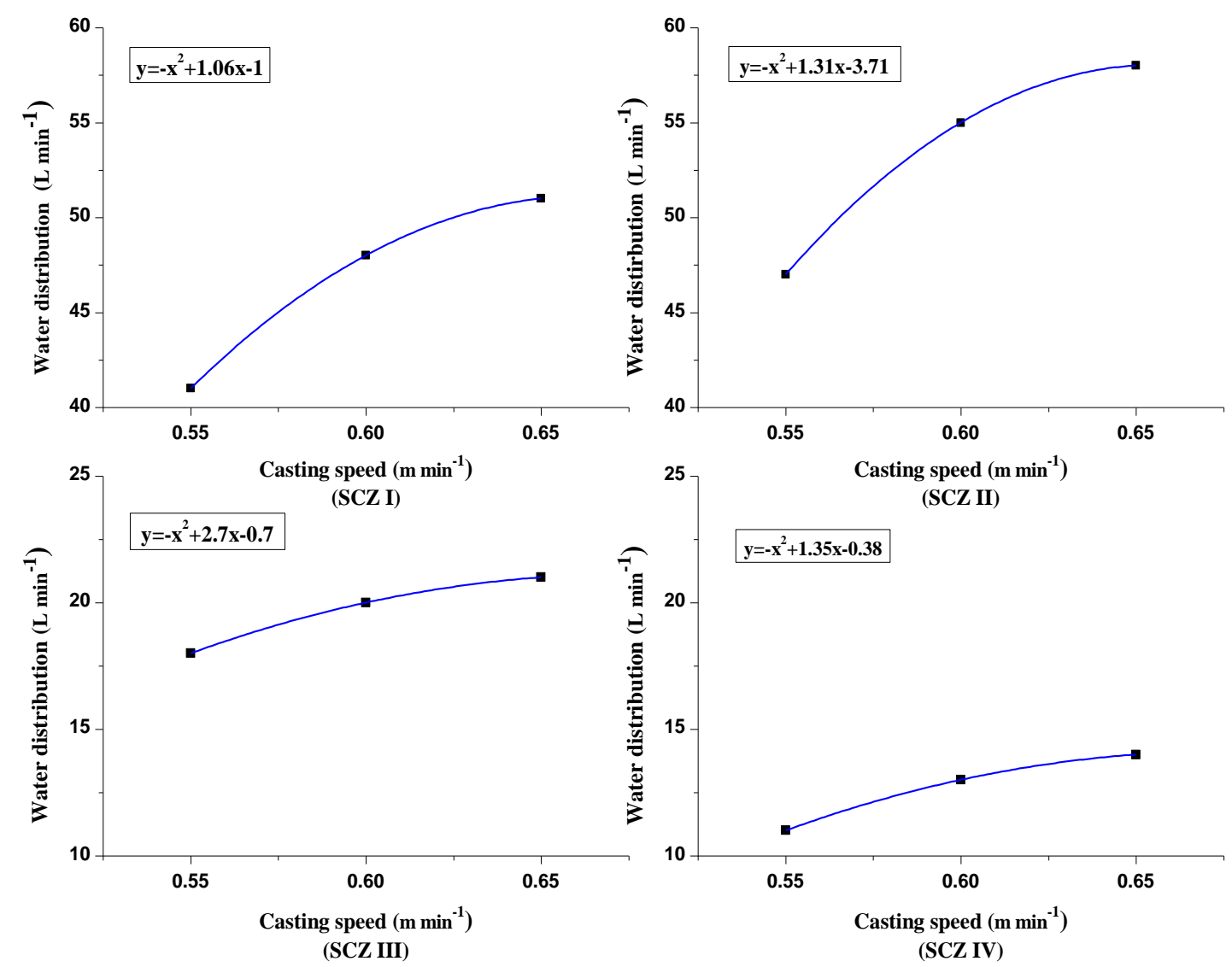

Fig. 4 The relationship of second cooling optimal water distribution and casting speed

\section{Conclusions}

In this paper, a heat transfer model is developed based on the bloom caster, in which the error is controlled less than 5\% compared to the measured temperature. It is evident that the application of IGA with a heat transfer model to simulate optimal operating conditions for a steel continuous caster is a powerful tool for optimizing the water flow of the secondary cooling process. The simulation generated by the IGA shows the modifications, which corresponds with the model quality and reduction in water consumption. The IGA with adaptive method in the crossover and mutation process can improve the optimized efficiency of the algorithm. It is found that the water consumption after optimization reduced by $2 \%$, compared to that of before optimization. In addition, the optimized function between the casting speed and the water flow rate is found, according to the analysis of the water flow of each cooling zone and casting speed.

\section{Acknowledgments}

The authors would like to thank the CSC Foundation of China, the National Natural Science Foundation of China (Nos. 51274057, 51474057) and the National High-tech R\&D Program of China (No.2012AA03A508).

\section{References}

1. B. Lally, L. T. Biegler and H. Henein: 'Optimization and continuous casting: Part I. Problem formulation and solution strategy', Metall. Trans. B, 1991, 22, 641-648. 
2. B. Lally, L. T. Biegler and H. Henein: 'Optimization and Continuous Casting: Part II. Application to Industrial Casters', Metall. Trans. B, 1991, 22, 649-659.

3. C. A. Santos, J. A. Spim, M. Ierardi and A. Garcia: 'The use of artificial intelligence technique for the optimization of process parameters used in the continuous casting of steel', Appl. Math. Model., 2002, 26, 1077-1092.

4. C. A. Santos, N. Cheung, A. Garcia and J. A. Spim: 'Application of a solidification mathematical model and a genetic algorithm in the optimization of strand thermal profile along the continuous casting steel', Mater. Manuf. Process, 2005, 20, 421-434.

5. C. A. Santos, J. A. Spim and A. Garcia: 'Mathematical modeling and optimization strategies (genetic algorithm and knowledge base) applied to the continuous casting of steel', Appl. Artif. Intel., 2003, 16, 511-527.

6. G. A. Toledo, J. Lainez and J.C. Cirion: 'Model optimization of continuous casting steel secondary cooling', Mater. Sci. Eng. A, 1993, 173, 287-291.

7. B. Z. Guo and B. Sun: 'Numerical solution to the optimal feedback control of continuous casting process', J. Global Optim., 2007, 39(2), 171-195.

8. N. Chakraborti, K. S. Kumar and G. G. Roy: 'A heat transfer study of the continuous caster mold using a finite volume approach coupled with genetic algorithms', J. Mater. Eng. Perform., 2003, 12(4), 430-435.

9. H. J. Meng, P. Zheng, R. Y. Wu and Z. Xie: 'Optimization and simulation of continuous casting secondary cooling based on enhanced PSO algotithm', J. Syst. Simul., 2006, 18(4), 866-869.

10. E. Laitinen and P. Neittaanmaki: 'On numerical simulation of the continuous casting process', J. Eng. Math., 1988, 22, 335-354.

11. D. Z. He: 'Continuous casting of steel', Metallurgical Industry Press, Beijing, 2007, 89-106.

12. D. E. Goldberg: 'GAs in Search Optimization and Machine Learning', Addison Wesley, Boston, 1989, 129-156.

13. Y. Sun and L. X. Hu: 'Modelling optimisation of hot processing parameters of Ti-6Al-4V alloy using artificial neural network and genetic algorithm', Materials Research Innovations, 2014, 18(S4), 1052-1056.

14. N. Chakraborti: 'Genetic algorithms in these changing steel times', Ironmaking \& Steelmaking, 2005, 32(5), 401-404. 


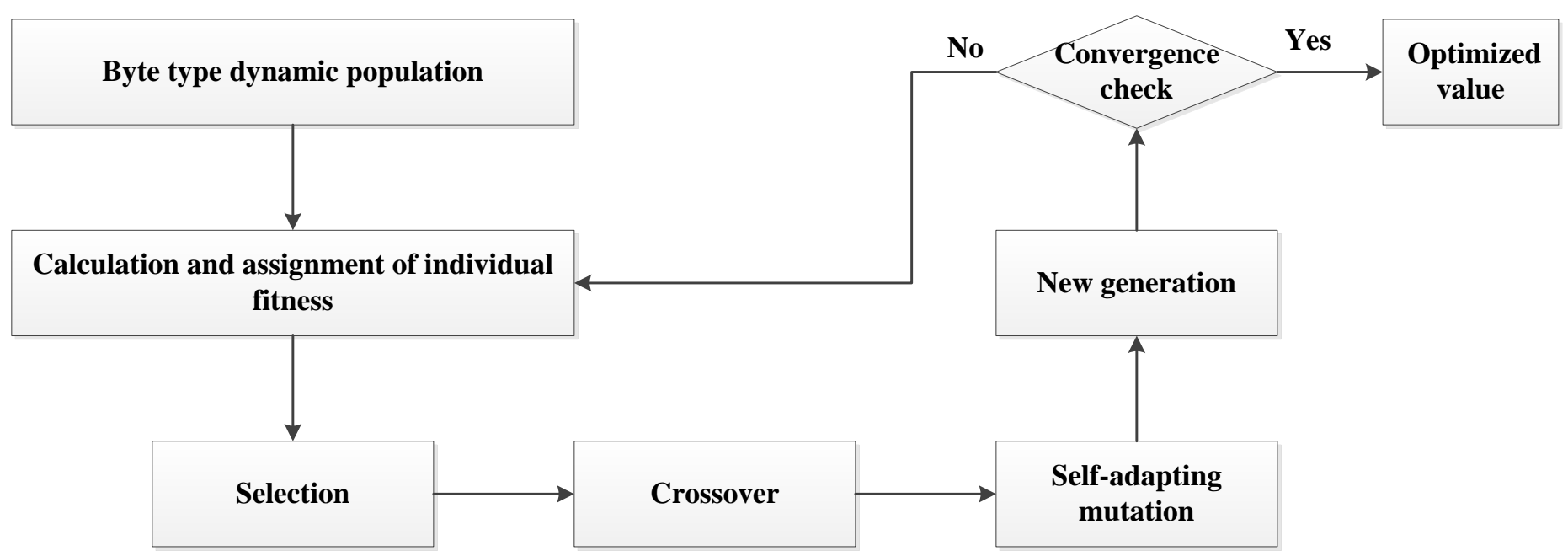

Fig. 1 Schematic diagram of the IGA procedure 


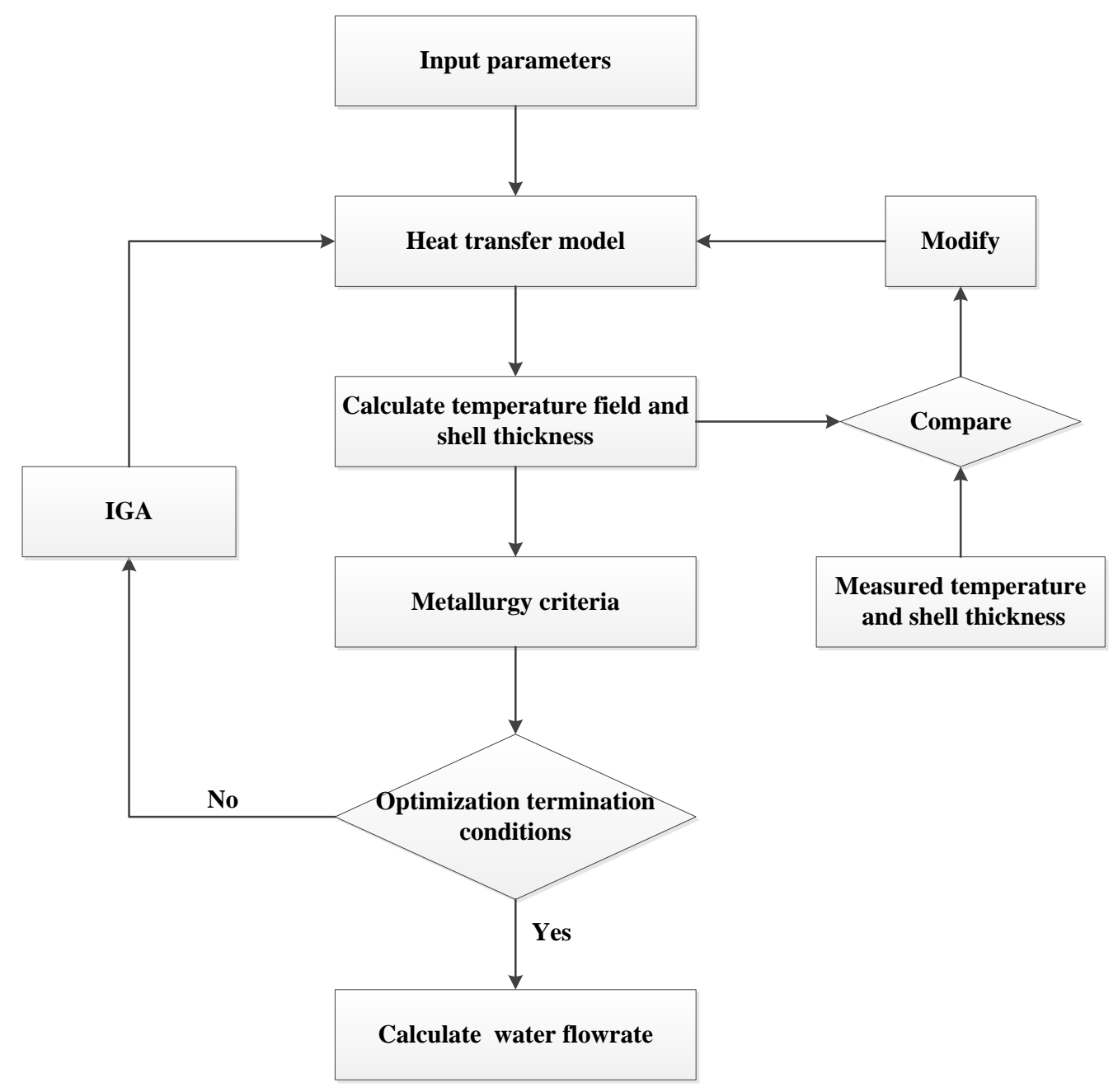

Fig. 2 Schematic diagram of the heat transfer model 


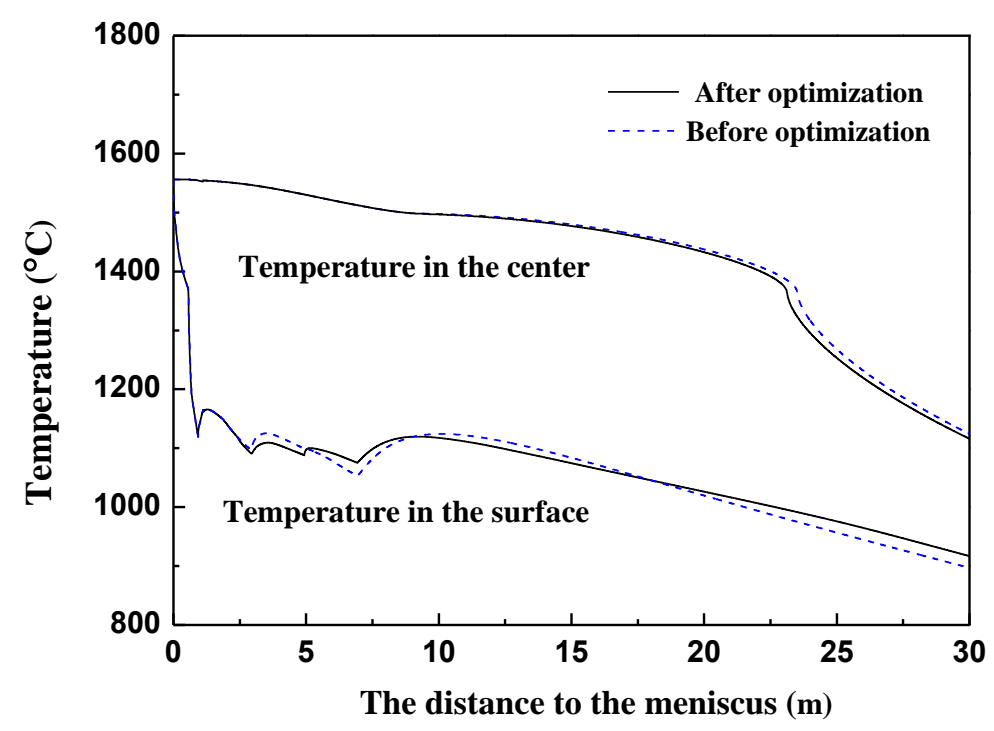

(a) Strand temperature

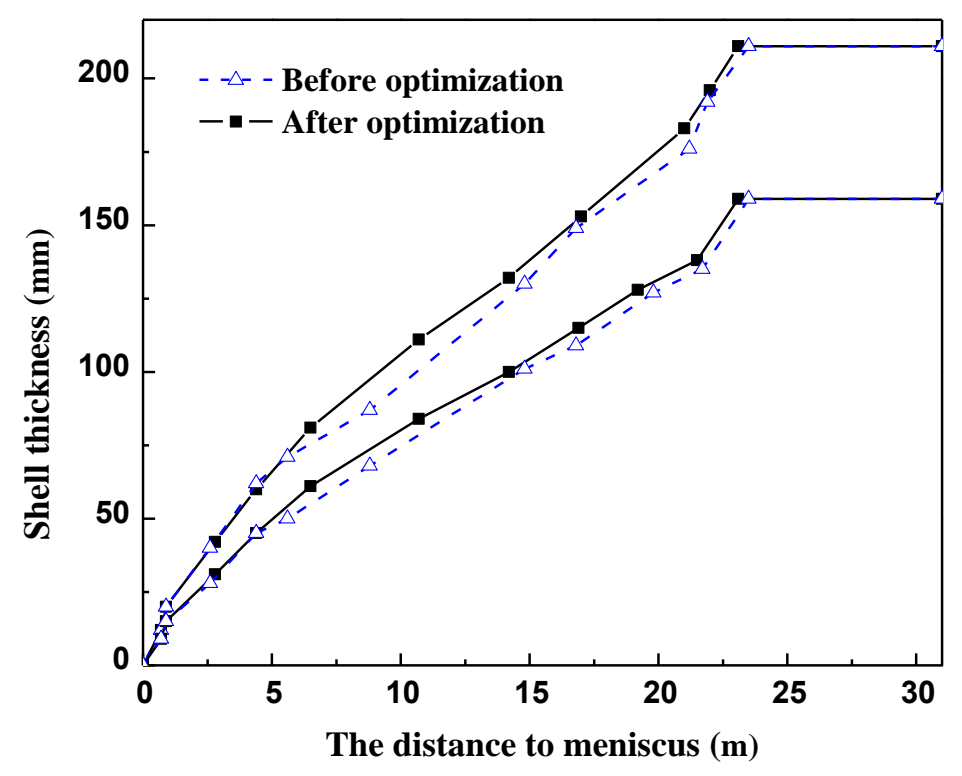

(b) Shell thickness

Fig. 3 Strand temperature and shell thickness before and after optimization with casting speed $0.6 \mathrm{~m} \mathrm{~min}^{-1}$ 

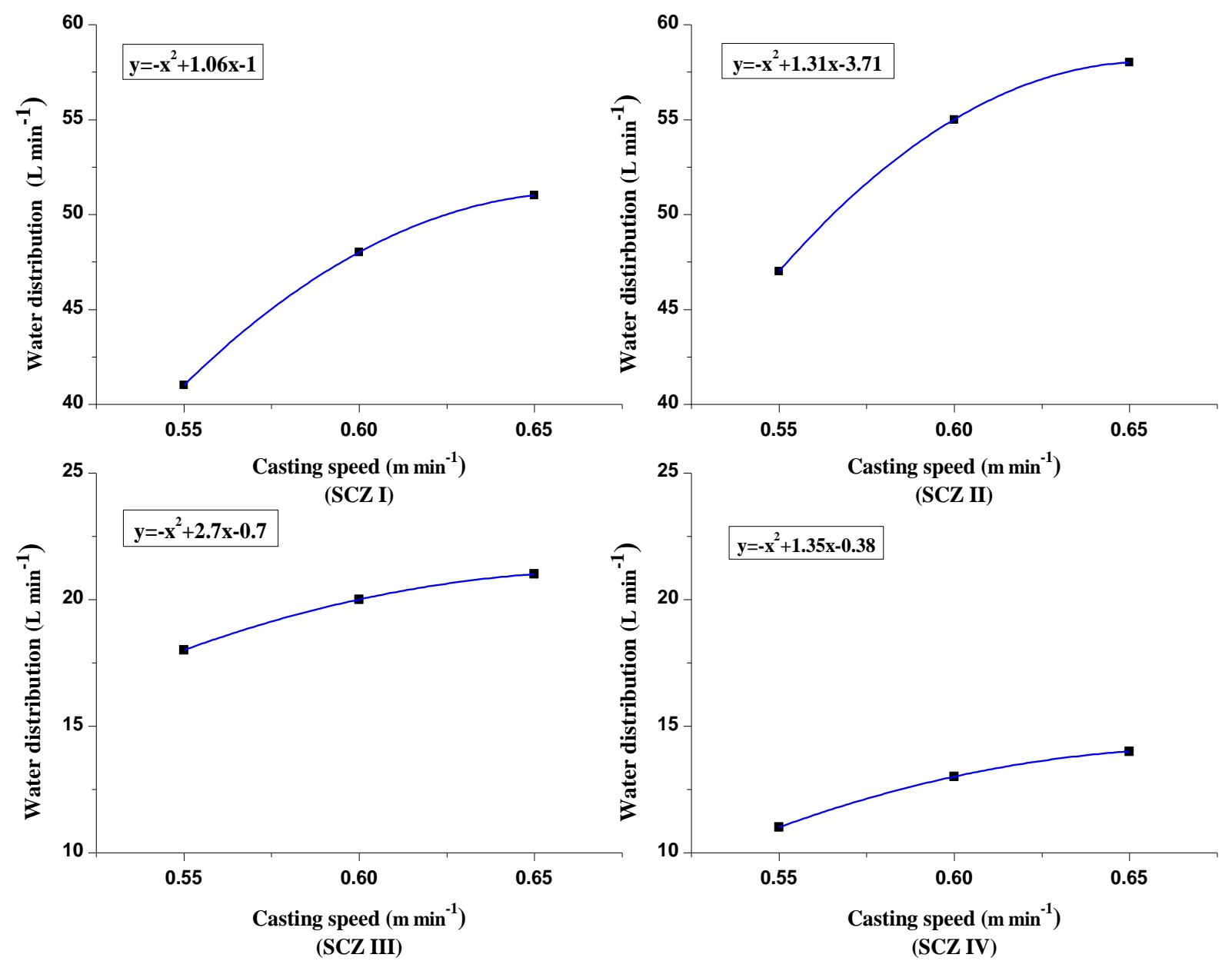

Fig. 4 The relationship of second cooling optimal water distribution and casting speed 